\title{
Predictive value of an early amplitude-integrated electroencephalogram for short-term neurologic outcomes in preterm infants
}

\author{
Kyung Hee Park ${ }^{1 \oplus}$, Young Mi Kim ${ }^{1 \oplus}$, Yun-Jin Lee ${ }^{2 \oplus}$, Mi Hye Bae ${ }^{1 \oplus}$, Na Rae Lee ${ }^{2 \oplus}$, \\ Young Mi Han ${ }^{2 \oplus}$, Hye-Young Kim ${ }^{1 \oplus}$, Su Young $\mathrm{Kim}^{2 \oplus}$, Shin Yun Byun ${ }^{2 \oplus}$ \\ ${ }^{1}$ Department of Pediatrics, Pusan National University Hospital, Pusan National University School of Medicine, Busan, Korea; \\ ${ }^{2}$ Department of Pediatrics, Pusan National University Children's Hospital, Pusan National University School of Medicine, Yangsan, \\ Korea.
}

\begin{abstract}
Background and objectives. The aim of this study was to compare serial scores of amplitude-integrated electroencephalography (aEEG) in preterm infants with favorable neurologic outcome compared with those with unfavorable neurologic outcome and to evaluate whether aEEG in the early days of life has predictive value for short-term neurologic outcome in preterm infants.

Methods. This prospective observational study included infants born at $\leq 32$ weeks of gestational age and $\leq 1,500 \mathrm{~g}$ of birth weight. On the basis of brain ultrasonography findings, the infants were divided into two groups (favorable and unfavorable outcome group) at 36 weeks of corrected age or at discharge. aEEG was performed at 12-14 h (day-1), 46-48 h (day-2), 70-72 h (day-3), and 1 week (day-7) of life. The aEEG recordings were analyzed using the criteria described by Burdjalov et al. ${ }^{23}$ and the serial scores of aEEG were compared between the two groups.

Results. Thirty five infants were enrolled and 18 infants and 17 infants were identified into both groups, respectively. Infants in the favorable outcome group showed high scores in almost all parameters and the score of all parameters increased over time. However, the scores of all components decreased in day-2 compared with those of day 1 in the unfavorable outcome group. The total score less than 3 of day- 2 has predictive value of $70.6 \%$ of sensitivity and $72.2 \%$ of specificity for unfavorable outcome.
\end{abstract}

Conclusion. We found that aEEG is a useful predictor for short-term neurologic outcome in preterm infants.

Key words: amplitude-integrated electroencephalography; preterm infant; neurological outcomes; periventricular leukomalacia.

The survival rate of preterm infants has increased dramatically owing to the advances in neonatal intensive therapy. ${ }^{1-3}$ However, this increased survival rate of preterm infants affects the morbidities such as intraventricular hemorrhage (IVH) and periventricular leukomalacia (PVL). The prevalence of brain damage and neurodevelopmental abnormalities

$凶$ Shin Yun Byun

byun410@gmail.com

Received 30th July 2019, revised 18th September 2019, accepted 17th October 2019. will also increase as the survival rate increases. ${ }^{4,5}$ Hence, monitoring of cerebral function has become important. However, it has not been generalized yet in neonatal intensive care units. Conventional electroencephalography (cEEG) has been the gold standard method for brain function monitoring for decades. Neonatal cEEG has been studied and correlated with neurodevelopmental outcomes in both fullterm and preterm infants with intracranial lesions. ${ }^{6-10}$ Because cEEG requires expertise in interpretation and is associated with some technical difficulties, it is difficult to routinely use in the neonatal intensive care 
units. ${ }^{11}$ On the contrary, amplitude-integrated electroencephalography (aEEG) can be recorded from a single-channel EEG and is easy to interpret. ${ }^{12}$ aEEG has become a bedside monitoring method in full-term asphyxiated infants and several studies have shown that an abnormal aEEG is predictive of the persistence of encephalopathy and impaired neurologic outcome when performed in the first few days of life. ${ }^{13-16}$ Recently, several studies have reported a correlation of early aEEG parameters with short- and long-term neurological outcome in preterm infants. ${ }^{17-22}$

In the present study, we used aEEG scoring system described by Burdjalov et al. ${ }^{23}$ to evaluate the relationship between scores of aEEG and unfavorable short-term neurologic outcome including IVH, PVL and death. We tried to compare serial scores of aEEG in the infants with favorable neurologic outcome compared with those with unfavorable neurologic outcome and to evaluate whether aEEG in the early days of life has predictive value of shortterm neurologic outcome in preterm infants.

\section{Material and Methods}

A prospective observational study was conducted on preterm infants born between December 2016 and November 2017 in Pusan National University Hospital. Infants were included if they were born at $\leq 32$ weeks of gestational age (GA) and weighed $\leq 1,500 \mathrm{~g}$ at birth. Infants were excluded if they had any of the following: 1) major congenital anomalies and/or chromosomal abnormality, 2) fetal hydrops, 3) metabolic disorders or central nervous system infection, or 4) death before 7days of life.

\section{Data collection}

The demographic characteristics were collected from the medical charts of the infants including the following parameters: GA, birth weight, sex, mode of delivery, 1 min and 5 min Apgar scores, initial arterial $\mathrm{pH}$, respiratory distress syndrome, patent ductus arteriosus (defined as the need for ibuprofen medication or surgical ligation), and hospital stay duration.

\section{Brain ultrasonography}

Brain ultrasonography was performed during the first 3 days of life and then mostly once a week, depending on the clinical course of the patient, until discharge, transfer or death. A Vivid 7 Dimension ultrasound machine (GE Healthcare, Waukesha, WI, USA) with an 8.0$\mathrm{MHz}$ transducer was used and the results were interpreted by 1 radiology specialist without knowing the history or the clinical status of the infants. Images were evaluated for germinal matrix-intraventricular hemorrhage according to the Papile ${ }^{24}$ classification (grade I-IV) and PVL according to the de Vries ${ }^{25}$ classification (grade I-IV). Short term neurologic outcome was assessed on the basis of ultrasonographic findings at 36 weeks of corrected age or at discharge. If there were different results on brain ultrasonography, the most recent was used. For the purpose of this study, Group A consisted of infants with favorable outcome which included normal brain lesions, IVH grade I or II, or PVL grade I or II. Group B consisted of infants who had unfavorable outcome including IVH grade III or IV, PVL grade III or IV, or death.

\section{Amplitude-integrated electroencephalography}

The aEEG recordings were performed in each infant four times: at $12-14 \mathrm{~h}, 46-48 \mathrm{~h}, 70-72 \mathrm{~h}$, and 7 days after birth. At least three hours were recorded for each time points. We used a cerebral function monitor (Olympic CFM 6000, Natus Medical Incorporated, San Carlos, USA) with disc electrodes prepared with Elefix paste (Nihon Kohden Corporation, Tokyo, Japan) to achieve low impedance. Single channel monitoring with attached over bi-parietal areas was done according to the international 10-20 EEG system. The quality of the aEEG trace was monitored using a simultaneous continuous impedance trace, and aEEG tracings with an impedance of $>20 \mathrm{k} \Omega$ were discarded. The aEEG tracings were interpreted according to a scoring system described by Burdjalov et al. ${ }^{23}$ (Table I). 
Table I. Cerebral function monitoring system reported by Burdjalov et al. ${ }^{25}$

\begin{tabular}{|c|c|c|c|c|}
\hline Score & Continuity & Cycling & $\begin{array}{l}\text { Amplitude of lower } \\
\text { border }\end{array}$ & $\begin{array}{l}\text { Bandwidth span and amplitude of } \\
\text { lower border }\end{array}$ \\
\hline 0 & Discontinuous & None & $\begin{array}{l}\text { Severely depressed } \\
(<3 \mu \mathrm{V})\end{array}$ & $\begin{array}{l}\text { Very depressed: low span }(\leq 15 \mu \mathrm{V}) \\
\text { and low voltage }(5 \mu \mathrm{V})\end{array}$ \\
\hline 1 & $\begin{array}{l}\text { Somewhat } \\
\text { continuous }\end{array}$ & Waves first appear & $\begin{array}{l}\text { Somewhat depressed } \\
(3-5 \mu \mathrm{V})\end{array}$ & $\begin{array}{l}\text { Very immature: high span }(>20 \mu \mathrm{V}) \\
\text { or moderate span }(15-20 \mu \mathrm{V}) \text { and low } \\
\text { voltage }(5 \mu \mathrm{V})\end{array}$ \\
\hline 2 & Continuous & $\begin{array}{l}\text { Not definite, somewhat } \\
\text { cycling }\end{array}$ & Elevated $(>5 \mu \mathrm{V})$ & $\begin{array}{l}\text { Immature: high span }(>20 \mu \mathrm{V}) \text { and } \\
\text { high voltage }(>5 \mu \mathrm{V})\end{array}$ \\
\hline 3 & & $\begin{array}{l}\text { Definite cycling, but } \\
\text { interrupted }\end{array}$ & & $\begin{array}{l}\text { Maturing: moderate span }(15-20 \mu \mathrm{V}) \\
\text { and high voltage }(>5 \mu \mathrm{V})\end{array}$ \\
\hline 4 & & $\begin{array}{l}\text { Definite cycling, non- } \\
\text { interrupted }\end{array}$ & & $\begin{array}{l}\text { Mature: low span }(<15 \mu \mathrm{V}) \text { and high } \\
\text { voltage }(>5 \mu \mathrm{V})\end{array}$ \\
\hline 5 & & $\begin{array}{l}\text { Regular and mature } \\
\text { cycling }\end{array}$ & & \\
\hline
\end{tabular}

Four components of the tracings were assessed: continuity (0-2), cycling (0-5), amplitude of the lower border (0-2), and bandwidth span and amplitude of lower border (0-4). These components were summated into a total score ranging from 0 to 13 . The aEEG tracings were interpreted by two independent researchers, who were blind to other information.

Ethical approval for this study was granted by the institutional review board of Pusan National University Hospital (1603-006-064). Fully informed written consent was obtained from the parents of all infants.

\section{Statistical analysis}

Data were stored in a dedicated access database and verified for accuracy. Statistical analyses were performed with SPSS 22.0 (IBM Corp., Chicago, IL, USA) using raw scores. To investigate the agreement between the aEEG interpretations of the two examiners, we performed Bland-Altman analyses. The analyses presented here focused on the comparisons between two groups (Group A and Group B). Statistical comparison of the categorical variables was tested by Fisher's exact test. Continuous variables were tested by independent t-test or Wilcoxon rank sum test depending on whether the data conformed to the normality assumption. p-value $<0.05$ was regarded as statistically significant. Receiver operating characteristic and area under the curve (AUC) were generated to determine cutpoints and to calculate the sensitivity and specificity. Youden's index was used to determine the optimal cutpoints on the probability scale for best discriminating between Group A and Group B. Youden's index was defined as the optimal cutpoint that maximizes both sensitivity and specificity.

\section{Results}

During the study period, 43 preterm infants born at $\leq 32$ weeks of GA and $\leq 1,500 \mathrm{~g}$ of birth weight were delivered at our hospital. Of them, 8 infants were excluded according to the exclusion criteria; congenital multiple anomaly $(n=1)$, fetal hydrops $(n=1)$, death before 7 days after birth $(n=4)$ or no parental consent $(n=2)$. Of the 35 included infants, 18 infants and 17 infants were identified into the Group A and $B$, respectively (Fig. 1). The demographic and clinical characteristics of both groups are shown in Table II.

The mean GA and birth weight were $29.3 \pm$ 2.2 weeks and $1139.5 \pm 316.8 \mathrm{~g}$, respectively in Group A. In Group B, the mean GA and birth weight was $28.0 \pm 2.6$ weeks and the mean 


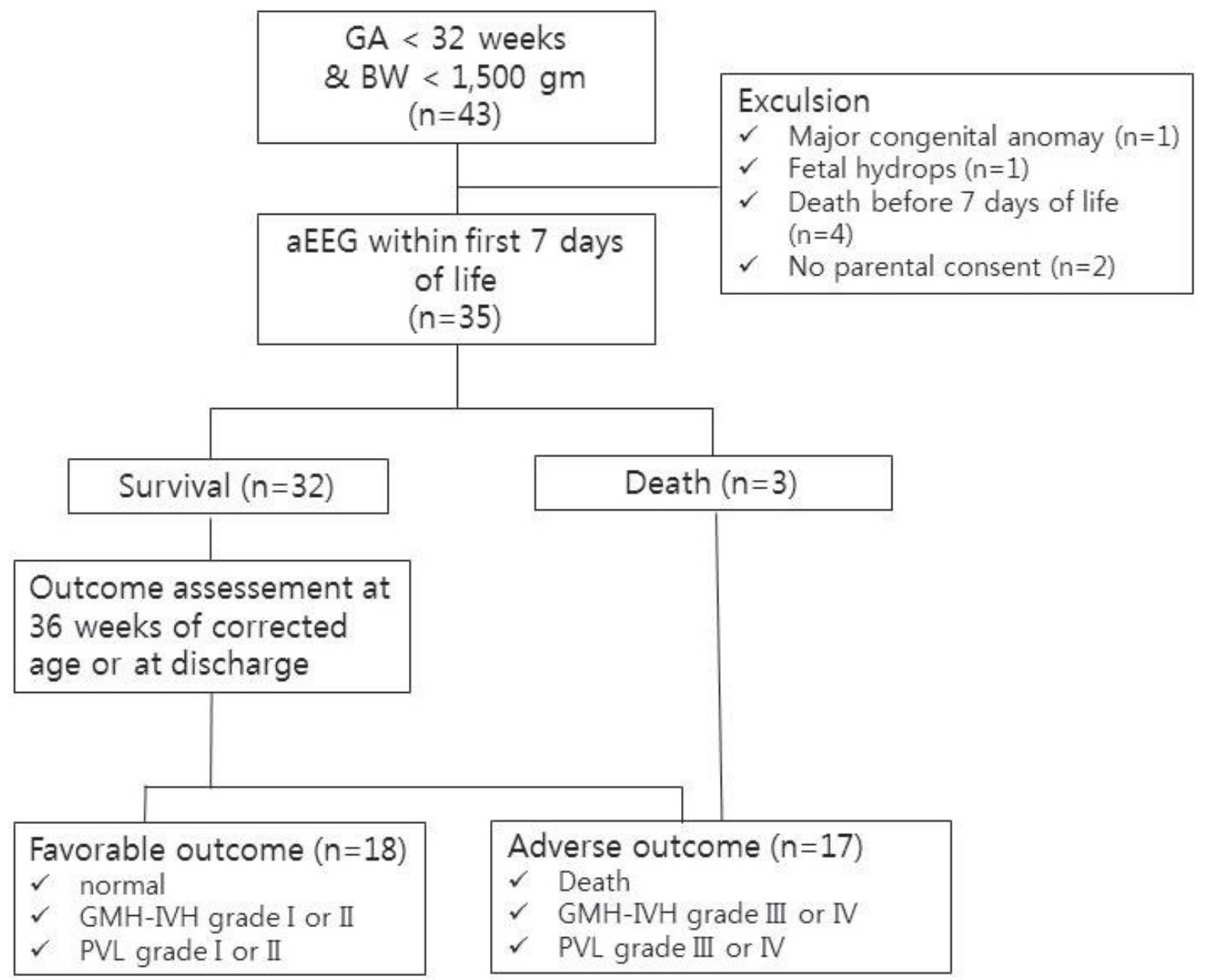

Fig. 1. Flowchart showing details of patients included and excluded.

BW: birth weight, aEEG: amplitude-integrated electroencephalography, GA: gestational age, GMH: germinal matrix hemorrhage, IVH: intraventricular hemorrhage, PVL: periventricular leukomalacia.

birth weight was $1023.0 \pm 345.9 \mathrm{~g}$ (Table II). There was no significant difference between the two groups in demographic and clinical characteristics including in sex, delivery mode, initial arterial $\mathrm{pH}$, incidence of patent ductus arteriosus, and hospital days. Initial systolic blood pressure and mean blood pressure were significantly lower in group B $(p=0.046$ and $p=0.011$ respectively) while incidence of respiratory distress syndrome was higher in group B ( $\mathrm{p}=0.025)$.

We performed the Bland-Altman analysis for total scores of Burdjalov score at each time points. The Bland-Altman plots show that most of the differences were within \pm 1.96
$\mathrm{SD}$, suggesting that the differences are not significant (Fig 2).

We found higher scores in all four component of each time point of the aEEG tracings in Group A than Group B and some of them had statistically significant differences. The mean score of continuity was significantly higher in group A (1.78) than that of group B (1.12) ( $p=$ 0.007 ). In case of cycling, patients in group $A$ had significantly higher mean scores at day 2 and day 7 ( $p=0.032$ and $p=0.042$, respectively). At the lower border, the only significant difference was at day-2, which was 1.17 and 0.94 in Group A and Group B, respectively ( $p=0.020)$. At the band width, patients in Group $A$ had 
Table II. Comparison of demographic and clinical characteristics between the two groups.

\begin{tabular}{lccc}
\hline Characteristics & Group A $(\mathrm{n}=18)$ & Group B $(\mathrm{n}=17)$ & $\mathrm{p}$ value \\
\hline Male gender, $\mathrm{n}(\%)$ & $10(55.6)$ & $11(64.7)$ & 0.733 \\
Gestational age, week & $29.3 \pm 2.2$ & $28.0 \pm 2.6$ & 0.114 \\
Birth weight, g & $1139.5 \pm 316.8$ & $1023.0 \pm 345.9$ & 0.308 \\
Cesarean section, $\mathrm{n}(\%)$ & $12(66.7)$ & $15(88.2)$ & 0.228 \\
Apgar score at 1 min. ${ }^{\S}$ & $5(4-7)$ & $4(3-6)$ & 0.095 \\
Apgar score at 5 min. ${ }^{\S}$ & $7(5-8)$ & $6(4-7)$ & 0.143 \\
Initial arterial pH & $7.4 \pm 0.1$ & $7.3 \pm 0.1$ & 0.191 \\
Systolic blood pressure, $\mathrm{mm} \mathrm{Hg}^{\S}$ & $58(38-80)$ & $43(32-87)$ & $0.046^{*}$ \\
Diastolic blood pressure, $\mathrm{mm} \mathrm{Hg}^{\S}$ & $29(18-64)$ & $21(13-59)$ & 0.064 \\
Mean blood pressure, $\mathrm{mm} \mathrm{Hg}^{\S}$ & $38(24-70)$ & $27(21-69)$ & $0.011^{*}$ \\
Ventilator support, $\mathrm{n}(\%)$ & $14(77.8)$ & $15(88.2)$ & 0.115 \\
Respiratory distress syndrome, $\mathrm{n}(\%)$ & $7(38.8)$ & $12(70.5)$ & $0.025^{*}$ \\
Patent ductus arteriosus, $\mathrm{n}(\%)$ & $5(27.7)$ & $10(58.8)$ & 0.061 \\
Hospital stay duration, day & $58(29-122)$ & $68(9-148)$ & 0.801 \\
\hline
\end{tabular}

Group A: infants with favorable outcome which included normal brain lesions, intraventricular hemorrhage (IVH) grade I or II, or periventricular leukomalacia (PVL) grade I or II.

Group B: infants who had unfavorable outcome including IVH grade III or IV, PVL grade III or IV, or death.

$\S$ Results are presented as median (25th percentile - 75th percentile).

Two-sample test or Wilcoxon rank-sum test for continuous variables; Fisher's exact test for categorical variables.

* $p$ value $<0.05$

higher mean scores but there is no significant difference. Total score was significantly higher at day-2 in group A (4.22 and 2.59, respectively).

All scores were increased as the postnatal days increased in Group A. However, there was a decrease in all four components of day-2 compared to day- 1 in Group B, and then after day-3, there was increase in all four components like in Group A (Fig 3). Especially there was a statistically significant increase in cycling in Group A, while all components except lower border were decreased significantly in group B at the day-2 (Table III).

Receiver operator characteristics curves were created to provide the predictive value of the total Burdjalov score for unfavorable outcome in preterm infants (Fig 4). AUC was highest at the day-2. The cutpoints for the mean total Burdjalov score at day-2 was set at 3 , as it presented the highest combined sensitivity and specificity, which were $70.6 \%$ and $72.2 \%$, respectively (Table IV).

\section{Discussion}

The tool to predict neurodevelopmental outcome in preterm infants would be helpful for accurate parental counseling and early rehabilitation programs if needed. Although reports describing usefulness of aEEG in predicting outcome of preterm infants have been limited, several reports showed that possibility of aEEG in predicting outcome of preterm infants. ${ }^{12,26,27}$ Chalak et al. ${ }^{12}$ reported that low voltage discontinuous activity with burst suppression was an ominous finding predicting the occurrence of severe intracranial hemorrhage with $100 \%$ positive predictive value and specificity. Kidokoro et al. ${ }^{26}$ reported that absent cycling on a EEG within 24 hour of age was associated with poor outcome in preterm infants.

Although there is still no consistent agreement in interpretation of recording in preterm infants, there are two common classifications and scoring systems of aEEG by HellströmHellström-Westas ${ }^{28}$ and Burdjalov et al. ${ }^{23}$ One 



Fig. 2. Each graph shows the Bland-Altman plots and 95\% confidence limits of the agreement between the 2 examiners for the total scores of aEEG from each time point. The mean of the examiners' scores is shown on the $x$-axis and differences are shown on the y-axis. The solid line indicates the mean differences between the examiners' scores, and the dashed lines indicate the 95\% confidence intervals of these differences. (D: day)

main difference between the two classifications is that the Burdjalov score is primarily designed to describe the physiological maturation of electrocortical activity. On the other hand, Hellstrom-Westas score is designed to distinguish pathological and physiological patterns rather than to describe maturational changes over time. ${ }^{29}$ We had evaluated the serial aEEGs during the first week of life with a scoring system described criteria by Burdjalov et $a . .^{23}$ in our previous study. ${ }^{30}$ At that study, we could confirm that the inter-rater agreement was high for most components of the tracing and that scoring system was objective and reproducible in repeated assessments of the aEEG tracing. Therefore, we adopted the criteria by Burdjalov et al. ${ }^{23}$ again in this study. We performed to determine the extent of agreement between the aEEG interpretations of the two examiners using Bland-Altman analyses, and could confirm that most of the differences were within $\pm 1.96 \mathrm{SD}$, suggesting that the differences are not significant.

Several reports demonstrated that the maturation of the aEEG tracing depends on GA and postnatal age in preterm infant. In our previous study, we examined the serial development of aEEG during the first week of life using Burdjalov scoring system to evaluate preterm infants who had no abnormality of brain ultrasounds. We found that the greater the GA, the more mature the aEEG tracing is at birth. In addition, that study showed that progressive increases with advancing postnatal age in all four component scores and the total score regardless of GA even though in 2426 weeks of GA. However, interestingly our 

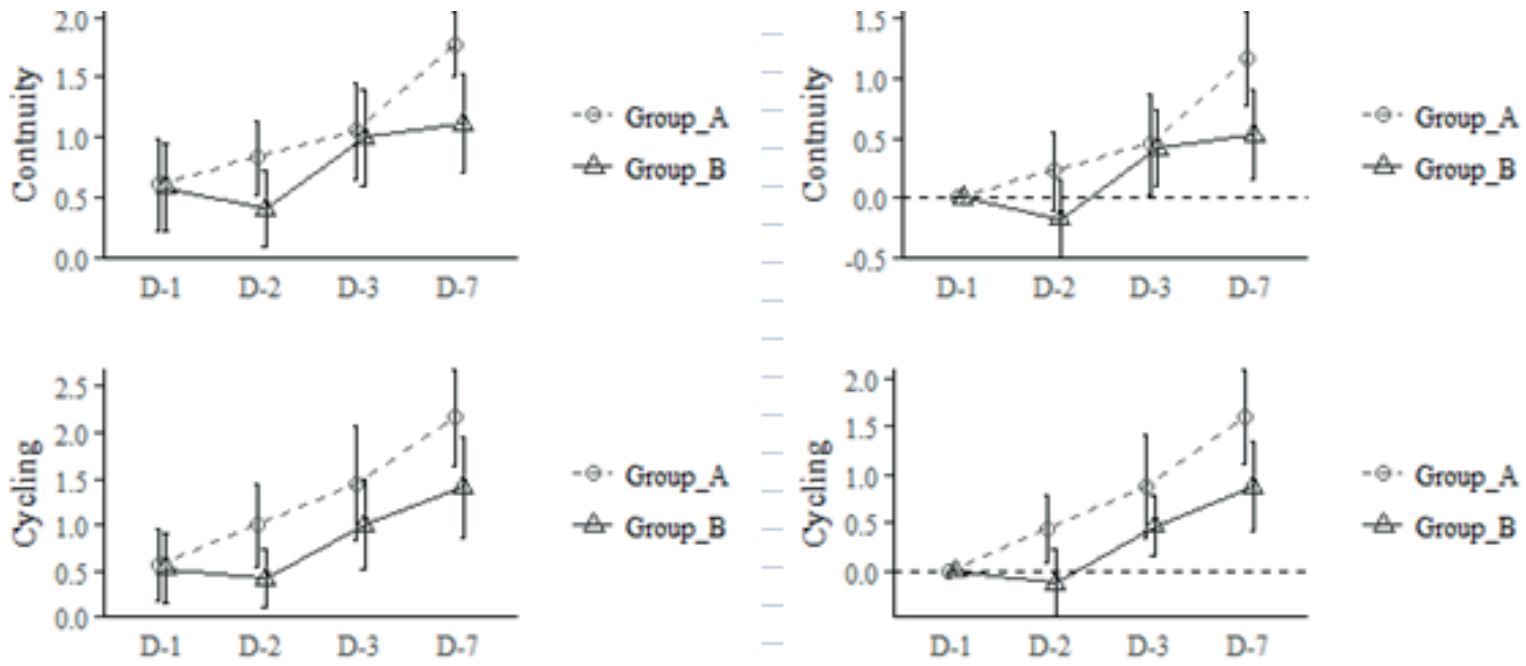

- $\ominus$. Group_A

- - - Group_A

Group_B
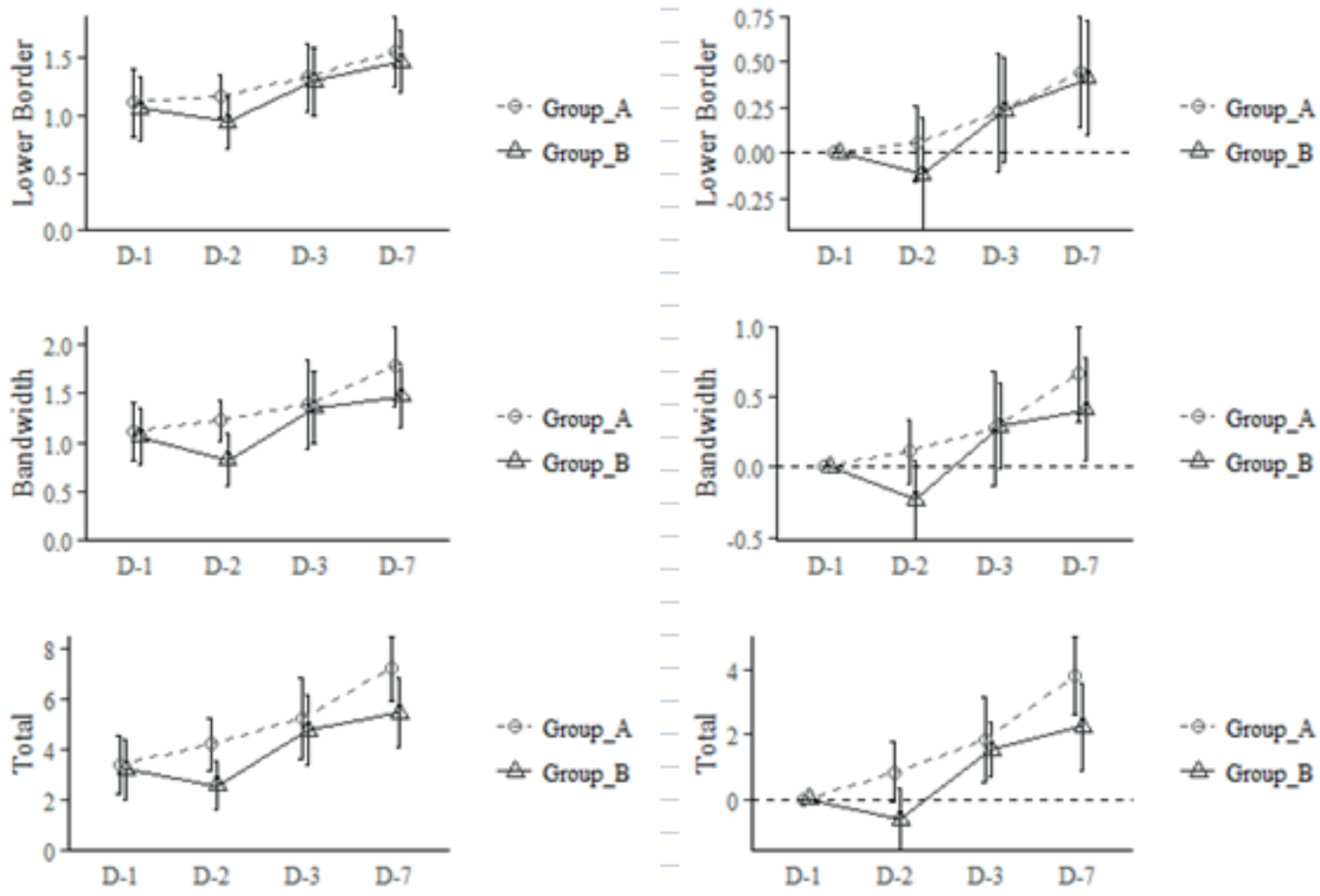

$-\Theta \cdot$ Group_A

Group_B

Fig. 3. Comparison of continuity, cycling, lower border, bandwidth and total score between the group A and the group B from each time points. The left side of the figure demonstrates the actual scores; the right side shows the differences from the first score. There was a decrease in all 4 components of day 2 compared with day 1 in group B. Then after day 3, there was an increase in all four components like in group A. (D: day)

results showed that scores of all components significantly decreased at day-2 compared with at day- 1 in group B, while the scores were increased as postnatal age increase in Group
A. In this study, GA and postnatal age did not differ between study groups. Therefore, those decreased score at day-2 in Group B might not be due to GA or postnatal age. 
Table III. Scores of components of aEEG at each time point.

\begin{tabular}{|c|c|c|c|c|}
\hline \multirow[b]{2}{*}{ Components } & \multicolumn{4}{|c|}{ Group A } \\
\hline & Day 1 & Day 2 & Day 3 & Day 7 \\
\hline Continuity & $0.61(0.78)$ & $0.83(0.62)$ & $1.06(0.80)$ & $1.78(0.55)$ \\
\hline Cycling & $0.56(0.78)$ & $1.00(0.91)$ & $1.44(1.25)$ & $2.17(1.04)$ \\
\hline Lower border & $1.11(0.58)$ & $1.17(0.38)$ & $1.33(0.59)$ & $1.56(0.62)$ \\
\hline Bandwidth & $1.11(0.58)$ & $1.22(0.43)$ & $1.39(0.92)$ & $1.78(0.81)$ \\
\hline \multirow[t]{2}{*}{ Total } & $3.39(2.33)$ & $4.22(2.13)$ & $5.22(3.26)$ & $7.22(2.53)$ \\
\hline & \multicolumn{4}{|c|}{ Difference of mean from baseline $(95 \% \mathrm{CI})$} \\
\hline Continuity & 0 (reference) & $0.22(-0.10,0.54)$ & $0.44(0.02,0.87) \dagger$ & $1.17(0.78,1.56)+$ \\
\hline Cycling & 0 (reference) & $0.44(0.09,0.79) \dagger$ & $0.89(0.35,1.43) \dagger$ & $1.61(1.12,2.10) \dagger$ \\
\hline Lower border & 0 (reference) & $0.06(-0.15,0.26)$ & $0.22(-0.10,0.54)$ & $0.44(0.14,0.75)+$ \\
\hline Bandwidth & 0 (reference) & $0.11(-0.12,0.35)$ & $0.28(-0.13,0.69)$ & $0.67(0.33,1.01)+$ \\
\hline \multirow[t]{3}{*}{ Total } & 0 (reference) & $0.83(-0.10,1.77)$ & $1.83(0.49,3.18)+$ & $3.83(2.64,5.03)+$ \\
\hline & \multicolumn{4}{|c|}{ Group B } \\
\hline & Day 1 & Day 2 & Day 3 & Day 7 \\
\hline Continuity & $0.59(0.71)$ & $0.41(0.62)$ & $1.00(0.79)$ & $1.12(0.78) *$ \\
\hline Cycling & $0.53(0.72)$ & $0.41(0.62)^{*}$ & $1.00(0.94)$ & $1.41(1.06)^{*}$ \\
\hline Lower border & $1.06(0.56)$ & $0.94(0.43) *$ & $1.29(0.59)$ & $1.47(0.51)$ \\
\hline Bandwidth & $1.06(0.56)$ & $0.82(0.53)$ & $1.35(0.70)$ & $1.47(0.62)$ \\
\hline \multirow[t]{2}{*}{ Total } & $3.24(2.33)$ & $2.59(1.84)^{*}$ & $4.76(2.68)$ & $5.47(2.74)$ \\
\hline & \multicolumn{4}{|c|}{ Difference of mean from baseline $(95 \% \mathrm{CI})$} \\
\hline Continuity & 0 (reference) & $-0.18(-0.50,0.15) \dagger$ & $0.41(0.09,0.73)$ & $0.53(0.16,0.90) \dagger$ \\
\hline Cycling & 0 (reference) & $-0.12(-0.48,0.24) \dagger$ & $0.47(0.15,0.79)$ & $0.88(0.41,1.36) \dagger$ \\
\hline Lower border & 0 (reference) & $-0.12(-0.43,0.19)$ & $0.24(-0.05,0.52)$ & $0.41(0.09,0.73)$ \\
\hline Bandwidth & 0 (reference) & $-0.24(-0.52,0.05) \dagger$ & $0.29(-0.01,0.60)$ & $0.41(0.05,0.78)$ \\
\hline Total & 0 (reference) & $-0.65(-1.61,0.31) \dagger$ & $1.53(0.67,2.38)$ & $2.24(0.89,3.58)$ \\
\hline
\end{tabular}

Group A: infants with favorable outcome which included normal brain lesions, intraventricular hemorrhage (IVH) grade I or II, or periventricular leukomalacia (PVL) grade I or II.

Group B: infants who had unfavorable outcome including IVH grade III or IV, PVL grade III or IV, or death.

Data are shown as mean (SD) except differences (95\% CI)

* $\mathrm{p}$ value $<0.05$ compared with Group A at same time points (two-sample test).

$+\mathrm{p}$ value $<0.05$ compared with baseline (day- 1 ) of the same parameter (two-sample test).

It is well known that the pathogenesis of the most common causes of disabling brain lesion such as IVH and PVL in preterm infants is likely to be associated with abnormalities of cerebral perfusion in the first days of life. ${ }^{31-33}$ Kehrer et al. ${ }^{33}$ performed quantitative measurement of cerebral blood flow volume using ultrasound flowmetry of the extracranial, brain feeding arteries in 32 preterm infants of 28-35 weeks of GA. They reported that the most pronounced increase in cerebral perfusion can be observed from the first to the second day of life in infants with normal brain and can be likely to represent a normal adaptive response of the cerebral circulation to postnatal conditions. Our results showed that scores of all components decreased significantly at day-2 compared with day-1 in Group B. The finding of this study is suggested that low score of aEEG might be due to failure of normal increase in cerebral perfusion during the first days of life, especially during the second day of life and therefore resulted in disabling brain lesions and adverse neurologic outcome sequentially. Interestingly, Bruns et al. ${ }^{29}$ reported that there is a correlation between absence of cycling on the second day 


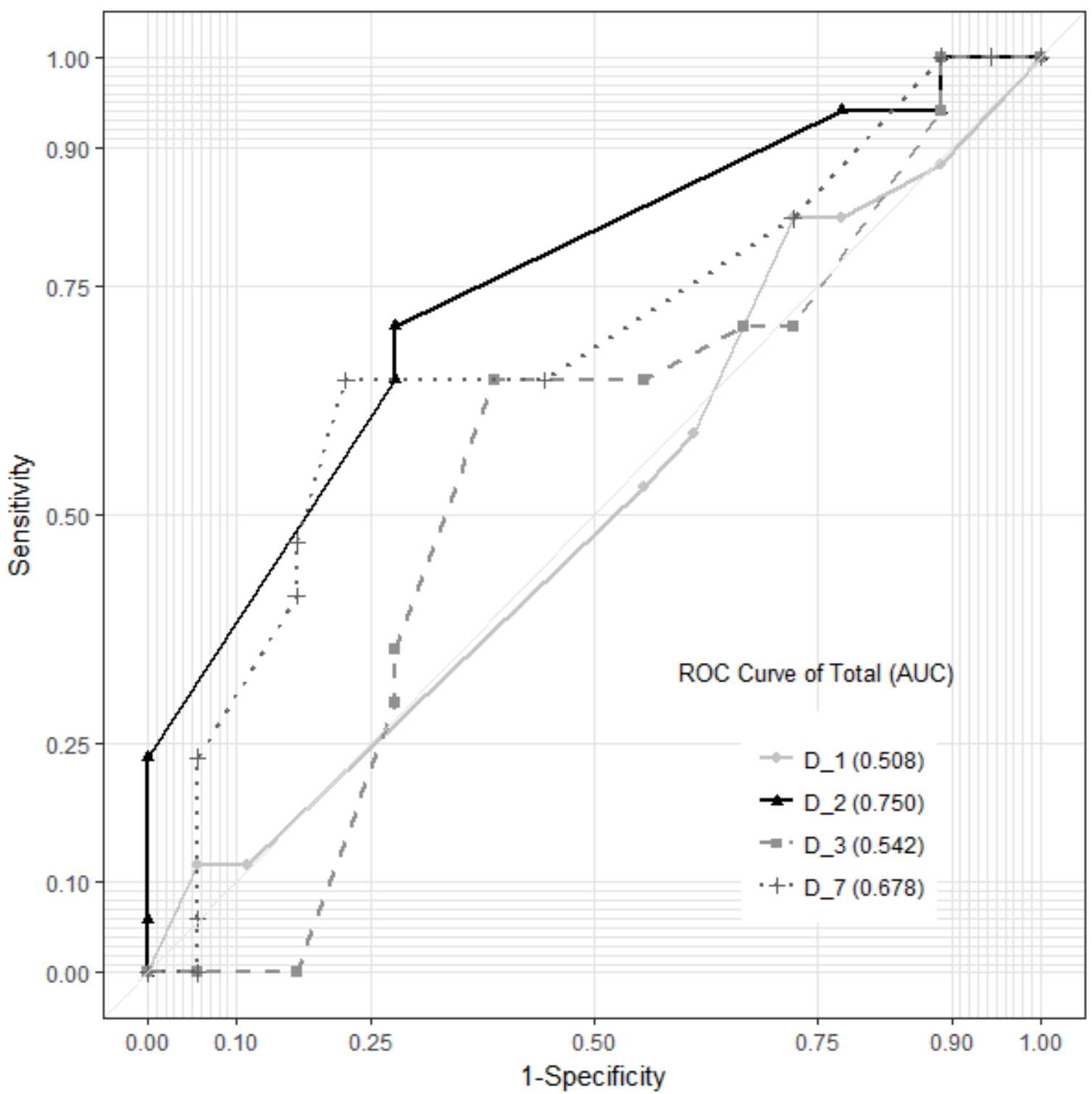

Fig. 4. Receiver operating characteristics curves calculated for total scores at each time point. The area under the curve is in brackets.

of life and the risk of death. In addition, Bowen et al. ${ }^{34}$ measured aEEG activity in the first 48 hour of life in preterm infants and identified that there was no increased in EEG continuity or a EEG amplitude for 12 to $48 \mathrm{~h}$ in neonates who died or developed grades 3-4 IVH. Their results were in substantial agreement with our study and supported our results. However, we could not measure cerebral blood flow. Further study using aEEG and cerebral blood flow will be needed to understand this phenomenon.
We also tried to identify a numerical value to predict neurodevelopmental outcome in preterm infants using scoring system by Burdjalov et al. ${ }^{23}$ We found that total score of day-2 has highest AUC and $\leq 3$ of total score has predictive value of $70.6 \%$ of sensitivity and $72.2 \%$ of specificity for the unfavorable outcome. In fact, there may be NICU in which continuous aEEG monitoring is not possible due to lack of equipment. In that case, it might be helpful that unfavorable prognosis can be estimated if a 
Table IV. Cutpoint, sensitivity and specificity of each time point in aEEG components.

\begin{tabular}{lcccccc}
\hline Components & Time & AUC & Cutpoint $^{\S}$ & Sensitivity & Specificity & p value \\
\hline Continuity & D-1 & 0.500 & 1 & $88.2 \%$ & $16.7 \%$ & NS \\
& D-2 & 0.683 & 0 & $64.7 \%$ & $72.2 \%$ & $0.025^{*}$ \\
& D-3 & 0.520 & 1 & $70.6 \%$ & $33.3 \%$ & 0.821 \\
Cycling & D-7 & 0.742 & 1 & $64.7 \%$ & $83.3 \%$ & $0.0099^{*}$ \\
& D-1 & 0.500 & 1 & $88.2 \%$ & $16.7 \%$ & NS \\
& D-2 & 0.696 & 0 & $64.7 \%$ & $72.2 \%$ & $0.018^{*}$ \\
\multirow{5}{*}{ Lower border } & D-3 & 0.598 & 1 & $70.6 \%$ & $50.0 \%$ & 0.249 \\
& D-7 & 0.685 & 1 & $52.9 \%$ & $77.8 \%$ & $0.047^{*}$ \\
& D-1 & 0.523 & 1 & $82.4 \%$ & $22.2 \%$ & NS \\
& D-2 & 0.603 & 0 & $11.8 \%$ & $100.0 \%$ & 0.276 \\
Bandwidth & D-3 & 0.518 & 1 & $64.7 \%$ & $38.9 \%$ & 0.954 \\
& D-7 & 0.556 & 1 & $52.9 \%$ & $61.1 \%$ & 0.716 \\
& D-1 & 0.523 & 1 & $82.4 \%$ & $22.2 \%$ & NS \\
& D-2 & 0.673 & 0 & $23.5 \%$ & $100.0 \%$ & 0.039 \\
& D-3 & 0.515 & 1 & $64.7 \%$ & $44.4 \%$ & 0.926 \\
& D-7 & 0.610 & 2 & $100.0 \%$ & $16.7 \%$ & 0.339 \\
& D-1 & 0.508 & 4 & $82.4 \%$ & $27.8 \%$ & NS \\
& D-2 & 0.750 & 3 & $70.6 \%$ & $72.2 \%$ & $0.004 *$ \\
& D-3 & 0.543 & 4 & $64.7 \%$ & $61.1 \%$ & 0.706 \\
& D-7 & 0.678 & 6 & $64.7 \%$ & $77.8 \%$ & 0.074 \\
\hline
\end{tabular}

\$Yuden-index, D: day

* $p$ value $<0.05$ compared from baseline in each parameters

AUC: area under the curve

score of $\leq 3$ is obtained by conducting a second day of life.

This study had several limitations including small number of patients. It is impossible to know exactly when the aEEG changed because aEEG was not monitored continuously during the first seven days of life. Our study also overlooked some minor problems such as hypotension during the hospital days although we know that those events also may associate with adverse neurologic outcome. Further studies with larger numbers and continuously monitored were needed. Despite of these limitations, we demonstrated that preterm infants with lower scores of aEEG especially during the second day of life than the first day of life or those with total scores $\leq 3$ during the second day of life are more likely to have shortterm unfavorable outcome.

\section{REFERENCES}

1. Blaymore-Bier J, Pezzullo J, Kim E, Oh W, GarciaColl C, Vohr BR. Outcome of extremely low-birthweight infants: 1980-1990. Acta Paediatr 1994; 83: 1244-1248.

2. La Pine TR, Jackson JC, Bennett FC. Outcome of infants weighing less than 800 grams at birth: 15 years' experience. Pediatrics 1995; 96: 479-483.

3. Piecuch RE, Leonard CH, Cooper BA, Sehring SA. Outcome of extremely low birth weight infants (500 to 999 grams) over a 12-year period. Pediatrics 1997; 100: 633-639.

4. Olischar M, Klebermass K, Waldhoer T, Polak A, Weninger M. Background patterns and sleep-wake cycles on amplitude-integrated electroencephalography in preterms younger than 30 weeks gestational age with peri-/intraventricular haemorrhage. Acta Paediatr 2007; 96: 1743-1750.

5. Wilson-Costello D, Friedman H, Minich N, Fanaroff AA, Hack M. Improved survival rates with increased neurodevelopmental disability for extremely low birth weight infants in the 1990s. Pediatrics 2005; 115: 997-1003. 
6. Tharp BR, Cukier F, Monod N. The prognostic value of the electroencephalogram in premature infants. Electroencephalogr Clin Neurophysiol 1981; 51: 219236.

7. Marret S, Parain D, Jeannot E, Eurin D, Fessard C. Positive rolandic sharp waves in the EEG of the premature newborn: a five year prospective study. Arch Dis Child 1992; 67: 948-951.

8. Maruyama K, Okumura A, Hayakawa E, Kato T, Kuno K, Watanabe K. Prognostic value of EEG depression in preterm infants for later development of cerebral palsy. Neuropediatrics 2002; 33: 133-137.

9. Okumura A, Hayakawa F, Kato T, Kuno K, Watanabe K. Developmental outcome and types of chronicstage EEG abnormalities in preterm infants. Dev Med Child Neurol 2002; 44: 729-734.

10. Kato T, Okumura A, Hayakawa F, Kuno K, Watanabe K. Electroencephalographic aspects of periventricular hemorrhagic infarction in preterm infants. Neuropediatrics 2004; 35: 161-166.

11. El-Dib M, Massaro AN, Glass P, et al. Early amplitude integrated electroencephalography and outcome of very low birth weight infants. Pediatr Int 2011; 53: 315-321.

12. Chalak LF, Sikes NC, Mason MJ, Kaiser JR. Low voltage aEEG as predictor of intracranial hemorrhage in preterm infants. Pediatr Neurol 2011; 44: 364-369.

13. Holmes G, Rowe J, Hafford J, Schmidt R, Testa M, Zimmerman A. Prognostic value of the electroencephalogram in neonatal asphyxia. Electroencephalogr Clin Neurophysiol 1982; 53: 6072.

14. Obrecht R, Pollock MA, Evans S, Scott DF. Prediction of outcome in neonates using EEG. Clin Electroencephalogr 1982; 13: 46-49.

15. Rowe JC, Holmes GL, Hafford J, et al. Prognostic value of the electroencephalogram in term and preterm infants following neonatal seizures. Electroencephalogr Clin Neurophysiol 1985; 60: 183196.

16. van Lieshout HB, Jacobs JW, Rotteveel JJ, Geven W, v't Hof M. The prognostic value of the EEG in asphyxiated newborns. Acta Neurol Scand 1995; 91: 203-207.

17. Benavente-Fernández I, Lubián-López SP, JiménezGómez G, Lechuga-Sancho AM, Garcia-Alloza M. Low-voltage pattern and absence of sleep-wake cycles are associated with severe hemorrhage and death in very preterm infants. Eur J Pediatr 2015; 174: 85-90.

18. Klebermass K, Olischar M, Waldhoer T, Fuiko R, Pollak A, Weninger M. Amplitude-integrated EEG pattern predicts further outcome in preterm infants. Pediatr Res 2011; 70: 102-108.
19. Reynolds LC, Pineda RG, Mathur A, et al Cerebral maturation on amplitude-integrated electroencephalography and perinatal exposures in preterm infants. Acta Paediatr 2014; 103: e96-e100.

20. Soubasi V, Mitsakis K, Sarafidis K, Griva M, Nakas CT, Drossou V. Early abnormal amplitude-integrated electroencephalography (aEEG) is associated with adverse short-term outcome in premature infants. Eur J Paediatr Neurol 2012; 16: 625-630.

21. Welch C, Helderman J, Williamson E, O'Shea TM. Brain wave maturation and neurodevelopmental outcome in extremely low gestational age neonates. J Perinatol 2013; 33: 867-871.

22. Wikström S, Pupp IH, Rosen I, et al. Early singlechannel aEEG/EEG predicts outcome in very preterm infants. Acta Paediatr 2012; 101: 719-726.

23. Burdjalov VF, Baumgart S, Spitzer AR. Cerebral function monitoring: a new scoring system for the evaluation of brain maturation in neonates. Pediatrics 2003; 112: 855-861.

24. Papile LA, Burstein J, Burstein R, Koffler H. Incidence and evolution of subependymal and intraventricular hemorrhage: a study of infants with birth weights less than 1,500 gm. J Pediatr 1978; 92: 529-534.

25. de Vries LS, Eken P, Dubowitz LM. The spectrum of leukomalacia using cranial ultrasound. Behav Brain Res 1992; 49: 1-6.

26. Kidokoro H, Kubota $\mathrm{T}$, Hayashi $\mathrm{N}$, et al. Absent cyclicity on aEEG within the first $24 \mathrm{~h}$ is associated with brain damage in preterm infants. Neuropediatrics 2010; 16: 241-245.

27. SohnJA, Kim HS, LeeEH, etal. Developmental change of amplitude-integrated electroencephalographic activity in preterm infants with intraventricular hemorrhage. Early Hum Dev 2013; 89: 961-966.

28. Hellström-Westas L, Rosen I, de Vries LS, Greisen G. Amplitude-integrated EEG classification and interpretation in preterm and term infants. NeoReviews 2006; 7: e76-e87.

29. Bruns N, Dransfeld F, Hüning B, et al. Comparison of two common aEEG classifications for the prediction of neurodevelopmental outcome in preterm infants. Eur J Pediatr 2017; 176: 163-171.

30. Han YM, Lee NR, Bae MH, et al. Establishing reference values for amplitude-integrated electroencephalography in preterms below 35 weeks of gestational age: a prospective observational cohort study. Turk J Pediatr 2016; 58: 592-601.

31. Krägeloh-Mann I, Toft P, Luding J, Andersen J, Pryds O, Lou HC. Brain lesions in preterm: origin, consequences and compensation. Acta Paediatr 1999; 88: 897-908. 
32. Volpe JJ. Neurobiology of the periventricular leukomalacia in the premature infant. Pediatr Res 2001; 50: 553-562.

33. Kehrer M, Blumenstock G, Ehehalt S, Goelz R, Poets C, Schöning M. Development of cerebral blood flow volume in preterm neonates during the first two weeks of life. Pediatr Res 2005; 58: 927-930.
34. Bowen JR, Paradisis M, Shah D. Decreased aEEG continuity and baseline variability in the first 48 hours of life associated with poor short-term outcome in neonates born before 29 weeks gestation. Pediatr Res 2010; 67: 538-544. 